\title{
Torakolomber Vertebra KırıklarındaPosterior Stabilizasyon Uygulanan Hastalarımızda Geç Dönem Sonuçlarımız
}

\section{Late Results of Posterior Stabilization in Patients with Thoracolumbar Vertebral Fractures}

\author{
Koray Tosyalı ${ }^{1 *}$, Sertan Hancıoğlu ${ }^{2}$, Serkan Erkan ${ }^{1}$ \\ $1 *$ Manisa Celal Bayar Üniversitesi Hastanesi, Ortopedi ve Travmatoloji Anabilim Dalı, Manisa, Türkiye \\ ${ }^{2}$ İzmir Sağlık Bilimleri Üniversitesi Tepecik Eğitim ve Araştırma Hastanesi, Ortopedi ve Travmatoloji Anabilim \\ Dalı, İzmir, Türkiye
}

e-mail: koraytosyali@hotmail.com,sertanh@hotmail.com,serkanerkan73@yahoo.com

Orcid: 0000-0002-1624-1912

Orcid: 0000-0002-8131-2254

Orcid: 0000-0001-6251-6991

*Sorumlu Yazar / Corresponding Author: Sorumlu Yazar: Koray Tosyalı

Gönderim Tarihi / Received: 20.04.2020

Kabul Tarihi / Accepted: 07.10.2020

DOI: $10.34087 /$ cbusbed.723625

\section{$\ddot{\mathrm{O} z}$}

Giriş ve Amaç: Bu çalışmada 2007- 2015 tarihleri arasında Ortopedi ve Travmatoloji Kliniğinde cerrahi yolla tedavi edilen Torakolomber vertebra kırı̆̆ bulunan 17 olgunun retrospektif değerlendirilmesi yapıldı.

Gereç ve Yöntemler: Çalışmaya dahil edilen hastaların en genci 20, en yaşlısı 63 yaşındaydı ve hastaların yaş ortalaması $43.05 \pm 13,25$ olarak belirlendi. Bu çalışmadaki 17 hastanın 9 ' u (\%52.9) kadın, 8'si (\%47.1) ise erkekti. Etyolojik faktör 7 olguda $(\% 41,2)$ yüksekten düşme, 7 olguda $(\% 41,2)$ trafik kazası, 2 olguda $(\% 11,8)$ araç dişı trafik kazası ve 1 olguda $(\% 5,9)$ darp idi. Olguların beşinde $(\% 29,4)$ L3, üçünde $(\% 17,6)$ L1, üçünde $(\% 17,6)$ T12,ikisinde $(\% 11,8)$ T8 ve bir hastada $(\% 5,9)$ T10 ,bir hastada $(\% 5,9)$ L2 ve bir hastada $(\% 5,9)$ L4 ve bir hastada da (\%5,9) L5 kırık idi. Hastaların \%82,4 ini patlama tarzı kırıklar oluşturmaktadır. Ek yaralanmalara bakıldığında ise en sık fibula şaft kırı̆̆ı yaralanması görülmektedir.

Bulgular: Hastaların hepsine posterior spinal segmental enstrumantasyon uygulandı. Tüm olgularda füzyon amacı ile hastanın kendi kemikleri karıștırılarak kullanıldı. Operasyonlarda ortalama 2,05 ünite kan kullanılmıștır.1 hastada implant kırılması ve yetmezliği görüldü. Hastaların ameliyat öncesinde , ameliyat sonrasında ve son kontrollerde klinik ve radyolojik sonuçları değerlendirildi. Ölçülen radyolojik parametreler ayakta yan grafilerde ; anterior korpus yükseklik kaybı, sagittal indeks , lokal kifoz açısı ,anterior kompresyon açısı yer almakta idi. Ayrıca 17 hastanın, ameliyat öncesi ve son kontrollerdeki bilgisayarlı tomografide transvers ve ön-arka spinal kanal çapları değerlendirildi. Son kontrollerde hastaların klinik gözlemleri vizüel analog skala (VAS), Roland -Morris skalası ve Oswestry skorlama sistemi kullanıldı ve değerlendirildi.

Sonuç: Klinik memnuniyette radyolojik parametrelerdeki düzelmeden ziyade kanal remodelasyonun daha etkın olduğu sonucuna vardık.

Anahtar kelimeler: Posterior stabilizasyon , Torakolomber vertebra, Vertebra Kırı

\section{Abstract}

Objective: In this study, we retrospectively evaluated 17 cases with thoracolumbar vertebra fractures who were surgically treated in Orthopaedics and Traumatology Clinics between the years January 2007 and June 2012.

Materials and Metods: In our cases mean age of the patient were 43.05 $\pm 13,25$ and the youngest patient was 20 years old whereas the oldest was 63 years old. In our study, $8(47.1 \%)$ of the 17 patients were male and $9(52.9 \%)$ of them were female. Etiological factor was falling from a height in $7(41,2 \%)$ cases, traffic accident in $7(41,2 \%)$ cases, out side traffic accident in $2(11,8 \%)$ cases and pounding in $1(5,9 \%)$ cases. In 5 cases $(29,4 \%)$ L3, in 3 cases $(17,6 \%)$ $\mathrm{L} 1$, in 3 cases $(17,6 \%) \mathrm{T} 12$,in 2 cases $(11,8 \%) \mathrm{T} 8$,in 1 cases $(5,9 \%) \mathrm{T} 10$,in 1 cases $(5,9 \%) \mathrm{L} 2$,in 1 case $(5,9 \%) \mathrm{L} 4$ 
,and in one case $(5,9 \%)$ L5 vertebrae was fractured. $82,4 \%$ of the patients have burst fractures. The most observed additional injury is fibula shaft fracture injury.

Results: Posterior spinal segmental instrumentation was performed in all casesThe radiological parameters were evaluated as loss of height in anterior corpus, sagittal index, local angle of kyphosis and anterior compresion angle in standing lateral radiographies. Moreover in 17 cases transverse and anteriorposterior spinal canal diameters were evaluated in CT assesment pre-operatively and during last controls. The clinical observation was made using visual analogue scala (VAS),Roland -Morris scala and Oswestry scoring system during last controls and the results were evaluated.

Conclusion: We conclude that canal remodelling is more effective than improvement in radiological parameters in clinical satisfaction.

Key words: Posterior stabilization, Thoracolumbar vertebra, Vertebra Fracture

\section{Giriş}

Omurga yaralanmaları, acil tanı ve tedavileri yoğun ve pahalı olan; yaralanma sonucu ortaya çıkabilen nörolojik sekeller nedeniyle uzun süren hasta bakımı gerektiren; hasta, hasta ailesi ve sosyal güvenlik sistemleri açısından hem ekonomik hem de sosyal maliyeti yüksek yaralanmalardı r[1]. Torakolomber omurga kırıklarının tedavisi oldukça tartışmalıdır. Tartışmanın önemli bir bölümü kırık sonrası omurga stabilitesinin etrafında dönmektedir. Benzer kırıklara koruyucu tedaviden, erken cerrahi tedaviye kadar çok çeşitli tedavi yöntemleri tanımlanmıştır [2]. Son 50 yıldır, vertebra kırıklarında, posterior ve/veya anterior yaklaşımla posterior, anterior veya kombine enstrümantasyon uygulamaları tedavide kullanılmakta olup, her üç seçenek ile elde edilen çok başarılı sonuçlar bildiren çalışmalar yayımlanmıştır $[3,4,5,6,7,8,9,10]$. Diğer taraftan hala herkesçe kabul edilebilir, geçerliliği ve güvenirliliği kanıtlanmış, bir torakolomber bölge kırık sınıflaması olmaması, cerrahi tedavide en çok başvurulan nörolojik yaralanma üzerinde cerrahi veya konservatif tedavinin benzer değişimlere yol açması, "spinal instabilite" kavramı konusunda hali hazırda bir kesinlik ve netlik olmaması torakolomber bölge kırıklarının tedavisi konusundaki karmaşanın sürmesine yol açmaktadır.

Bu çalışmanın amacı; kliniğimize torakolomber omurga kırı̆̆ 1 nedeniyle yatırılan ve cerrahi tedavi uygulanan olguların retrospektif olarak yaş, cinsiyet, yaralanma nedeni,nörolojik durum, kırık seviyesi, kırık tipi, yapılan cerrahi girişim, birlikte olan yaralanmalar, gelişen komplikasyonlar saptanarak, klinik ve radyolojik sonuçlarımız ile birlikte literatürle karşılaştırmak ve sonuçlarını tartışmaktır.

\section{Materyal ve Metod}

Manisa Celal Bayar Üniversitesi Hastanesi Ortopedi ve Travmatoloji Kliniğinde Ocak 2007- Haziran 2012 tarihleri arasında yatırılan torakolomber omurga kırıklı 65 hastadan cerrahi uygulanan 28 hasta incelenmiştir . $\mathrm{Bu}$ süre içinde ameliyat defterleri,epikriz raporları ve arşiv dosyalarından belirlenilen 28 hastadan bir tanesi ameliyatının birinci haftasında yoğun bakımda ex olmuştur, 1 hastanın evsiz olması ve 9 hastanın da adres değişikliği yapması sonucunda 17 hasta ile çalışmamız tamamlanmıştır.

Çalışmada tüm hastaların kırıkları TLISS ve Dennis sınıflamasına göre sınıflandırılmıştır. Hastaların cerrahi öncesi, cerrahi sonrası ve son kontrollerindeki klinik verileri VAS, Oswestry, Roland Moris ve Frankel skalaları ile değerlendirilmiştir. İlk muayeneden sonra, hassasiyeti olan ağrilı bölgelerin, servikal ve torakolomber bölgenin iki yönlü grafileri, grafiler görüldükten sonra ise şüpheli alanların lokalize bilgisayarlı tomografileri görülmüştür. Nörolojik defisit varlığında acil MR görüntülemeleri yapılmıştır.

Verilerin analizi SPSS Windows 21.0 paket programında istatistik analiz uzmanı tarafindan Genel lineer modellerden tekrarlı ölçümler analizi kullanılarak yapıldı. $\mathrm{p}<0,05$ için sonuçlar istatistiksel olarak anlamlı kabul edildi. İkili karşılaştırmalar Bonferoni testi ile yapıldı. Tanımlayıcı istatistikler sürekli değişkenler için ortanca (minimummaksimum), kategorik değişkenler için yüzde (\%) olarak verildi. Spinal kanal çapları arasındaki değişiklikler student T-testi kullanılarak analiz edildi.

\section{Bulgular ve Tartışma}

Olgularımızın 9 'u (\%52.9) kadın, 8 'i (\%47.1) ise erkekti. Omurga kırıkları erkeklerde daha fazla görülmekte olup, olgularımızdaki erkek/kadın oranı literatür ile uygunluk göstermemektedir[11,12,13,14]. Hastaların yaş dağılımı en küçük 20 ve en büyük 63 olmak üzere ortalama $43.05 \pm 13,25$ dir. Kadınlar ortalama $44.44 \pm 12,56$ yaşındaydı. Erkeklerde ortalama yaş ise 41,05 $\pm 14,69$ 'dir. Yerli ve yabancı serilerde torakal ve lomber omurga kırıkları genellikle üçüncü dekadda sık görülmekte olup, serimizde bu gözlenmiştir. $\mathrm{Bu}$ yaşlardaki insanların aktif yaşam mücadelesi içerisinde olmaları yaralanma olasılığını da arttırmaktadır [11,12,13,14].

Hastaların başvuru zamanlarına bakıldığında $8(\% 47.1)$ hasta ilk 8,4 hasta $(\% 23,5) 8$-24 ve $5(\% 29,4)$ hasta da 24 saatten sonra kliniğimize başvurmuştur. Hastaların ortalama hastanede kalış süresi $15,52 \pm 7,8$ gün idi. Omurga kırıklarının hastanede kalma süresinin uzun olmasının nedeni yaralanmanın şiddetli travmalar ile olması nedeniyle ek yaralanmaların bulunması, sıklıkla olan nörolojik yaralanma sonucu hastanın rehabilitasyonundaki güçlüklerdir $[15,16]$. Travma tiplerine göre $7(\% 41,2)$ yüksekten düşme ve $7(\% 41,2)$ araç içi trafik kazası olmak üzere en sık travma şekilleri idi. Bunu sırasıyla $2(\% 11,8)$ araç dışı trafik kazası ve 1 $(\% 5,9)$ darp takip ediyordu. 


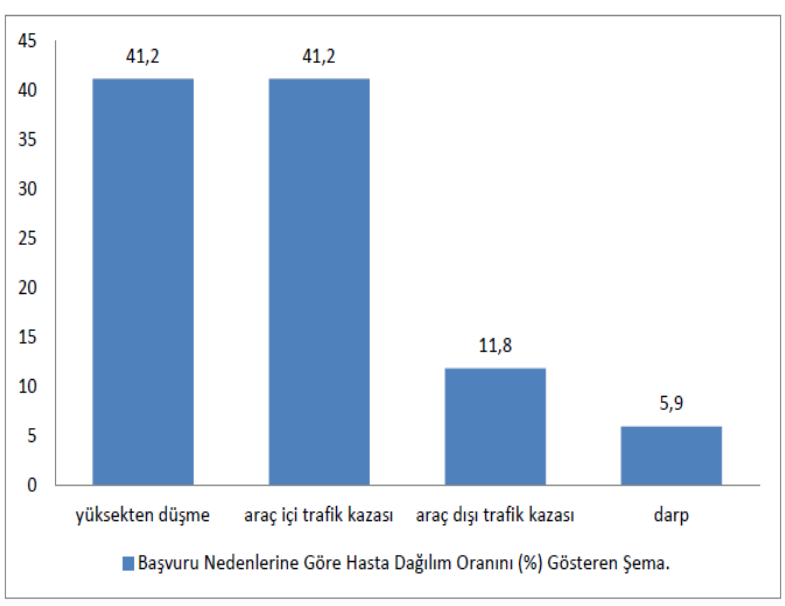

Şekil 1. Başvuru nedenlerine göre hasta dağılım oranı

Olguların beşinde $(\% 29,4)$ L3, üçünde $(\% 17,6)$ L1, üçünde $(\% 17,6)$ T12, ikisinde $(\% 11,8)$ T8 ve bir hastada $(\% 5,9)$ T10 ,bir hastada $(\% 5,9)$ L2 ve bir hastada $(\% 5,9)$ L4 ve bir hastada da $(\% 5,9)$ L5 kırık idi . Hastalarımızın \%35,2 si kırık seviyesi torakolomber (T11-L2) bölgede idi. Torakolomber bölge torakal kifoz ve lomber lordozun birleşme yeri olması, torakal bölgenin rotasyon hareketlerine ve lomber bölgenin fleksiyon hareketlerine izin vermesi, bu bölgenin ara geçiş bölgesi olması nedeniyle zorlamalara olan direnci azaltarak omurga kırıklarının en sık bu bölgede görülmesine yol açmaktadır. Diğer bir özelliği de vücut yerçekimi ekseninin bu yerleşme yerinde omur cismi üzerinden geçmesi ve aksiyel kompresyon güçlerinin omurganın aşağı kesimlerinde yukarı kesimlere oranla daha etkili olmasidir $[15,16]$.

Hastaların 8'inde eşlik eden yaralanmalar mevcuttu. 2 hastada medial maleol kırığı, 2 hastada fibula şaft kırığı, 1 hastada tibia plato kırığı, 1 hastada klavikula kırığ 1,1 hastada tibia ve fibula şaft kırı̆̆ı, ve 1 hastada da pelvis kırığı(iliak kanat,bilateral iskion pubik kol ,sakroiliak çıkık), olecranon ve talus kırığı mevcuttu.

Kırık tipleri olarak 14 olguda $(\% 82,4)$ patlama tarzı en fazla gözlenen kırık tipiydi. Bunu 2 olguda (\%11.8) anterior kompresyon kırığı ve 1 olguda $(\% 5,9)$ kırıklı çıkık takip ediyordu.

Tablo 1. Kırık Morfolojisi Dağılımı

\begin{tabular}{|l|l|l|}
\hline Kırık tipi & Sayı & $\%$ \\
\hline $\begin{array}{l}\text { Anterior } \\
\text { Kompresyon }\end{array}$ & 2 & 11,8 \\
\hline Burst & 14 & 82,4 \\
\hline Kırıklı çıkık & 1 & 5,9 \\
\hline Toplam & 17 & 100 \\
\hline
\end{tabular}

Hastaların ortalama operasyon süresi $184,1 \pm 42,5 \mathrm{dk}$ idi.Operasyonda kullanılan ortalama kan kaybı 2,05 ünite idi. Nörolojik defisiti olan 5 hastaya $(\% 29,4)$ ilk 1 saatte $30 \mathrm{mg} / \mathrm{kg} / \mathrm{saat}$ Prednisolon yükleme dozu yapıldı, daha sonraki 23 saat boyunca $5,4 \mathrm{mg} / \mathrm{kg} / \mathrm{saat}$ dozunda devam edildi.

Tanımlayıcı analiz sonuçlarına bakıldığında hastaların tedavi öncesi ortalama lokal kifoz açıları $19,4^{\circ} \pm$ $6,2^{\circ}\left(\min .9^{\circ} \max \cdot 32^{\circ}\right)$. Ameliyat sonrası lokal kifoz açıları ortalama $8,7^{\circ} \pm \quad 6,5^{\circ}\left(\min .2^{\circ} \max 20^{\circ}\right)$ 'dir. Son kontrollerindeki lokal kifoz açıları ortalama $10,6^{\circ} \pm 5,4^{\circ}\left(\min .3 \max .21^{\circ}\right)$ 'dir. $\mathrm{Bu}$ açılar arasındaki değişimlerin ilişkili örneklem tek yönlü varyans analizinde ameliyat öncesi ve sonrası lokal kifoz açısındaki azalmalar istatistiksel açıdan anlamlı bulundu( $(\mathrm{p}<0,05)$. Bu sonuçlara göre hastaların yapılan cerrahiden lokal kifoz açısının düzeltilmesi açısından radyolojik fayda gördüklerini saptadık. $\mathrm{Bu}$ fayda istatistiksel olarak anlamliyd $1(\mathrm{p}<0,05)$.

Tanımlayıcı analiz sonuçlarına göre hastaların tedavi öncesi ortalama sagittal indeksleri 20,4 $\pm 9,3$ (min. 3 max. 36). Ameliyat sonrası sagittal indeksleri ortalama 13,1 1 7,5 (min. 4 max. 34)'dir. Son kontrollerin sagittal

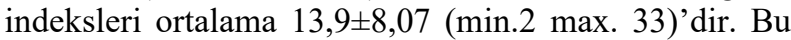
sonuçlara göre hastaların yapılan cerrahiden sagittal indekslerin düzeltilmesi açısından radyolojik fayda gördüklerini saptadık. Bu fayda istatistiksel olarak anlamliyd $(\mathrm{p}<0,05)$.

Tanımlayıcı analiz sonuçlarına göre hastaların tedavi öncesi ortalama anterior kolon çökme miktarları $\% 40,5 \pm 14,6$ ( $\min . \% 12 \max$ \%62). Ameliyat sonrası anterior kolon çökme miktarları ortalama \%21,2 \pm 8,7(min. \%8 max. \%36)'dir. Son kontrollerindeki anterior kolon çökme miktarları ortalama \%28,15 \pm 15 (min.\%8 max. \%58)'dir. Bu sonuçlara göre hastaların yapılan cerrahiden anterior kolon yüksekliğinin tekrar sağlanması açısından radyolojik fayda gördüklerini saptadık. $\mathrm{Bu}$ fayda istatistiksel olarak anlamliyd $1(\mathrm{p}<0,05)$.

Tanımlayıcı analiz sonuçlarına bakıldığında hastaların tedavi öncesi ortalama anterior kompresyon açıları $21,2^{\circ} \pm 8,7^{\circ}\left(\min .8^{\circ} \max \cdot 36^{\circ}\right)$. Ameliyat sonras1 anterior kompresyon açıları ortalama $9,2^{\circ} \pm 4,2^{\circ}\left(\min .3^{\circ}\right.$ $\left.\max 20^{\circ}\right)^{\prime}$ dir. Son kontrollerindeki anterior kompresyon açıları ortalama $11,4^{\circ} \pm 5,4\left(\min .3 \max .21^{\circ}\right)$ 'dir. Bu sonuçlara göre hastaların yapılan cerrahiden lokal kifoz açısının düzeltilmesi açısından radyolojik fayda gördüklerini saptadık. Bu fayda istatistiksel olarak anlamliyd 1 ( $<<0,05)$.

Anket uygulanan 17 hastanın Oswestry anket skorları ortalama 22,2 $\pm 11,8$ (min.0 max.42,8 )'dir. Anket sonuçlarına göre grade I olgu sayısı $9(\% 52,9)$, grade II olgu sayıs $5(\% 29,4)$ ve grade III olgu sayısı $2(\% 11,7)$ olarak değerlendirildi.

Anket uygulanan 17 hastanın Roland -Morris skorları ortalama 10,7 $\pm 3,8(\min .2 \max .17$ )'dir. Hastaların son kontrolleri sirasında ortalama VAS (vizüel analog skala) skoru 4,1 $\pm 1,9$ (min. 0 max.7) dur.

Spearman's rho testine göre ameliyat sonrası kanal remodelasyon oranı ile VAS skoru, Oswestry skoru ve Roland-Morris skoru arasında istatistiksel olarak doğrusal negatif bir ilişkinin( $\mathrm{r}=-0,816, \quad \mathrm{r}=-0,656 \mathrm{r}=-$ 0,808 ) olduğunu saptadık. Bu ilişki istatistiksel olarak anlamliydı $(\mathrm{p}<0,05)$. 


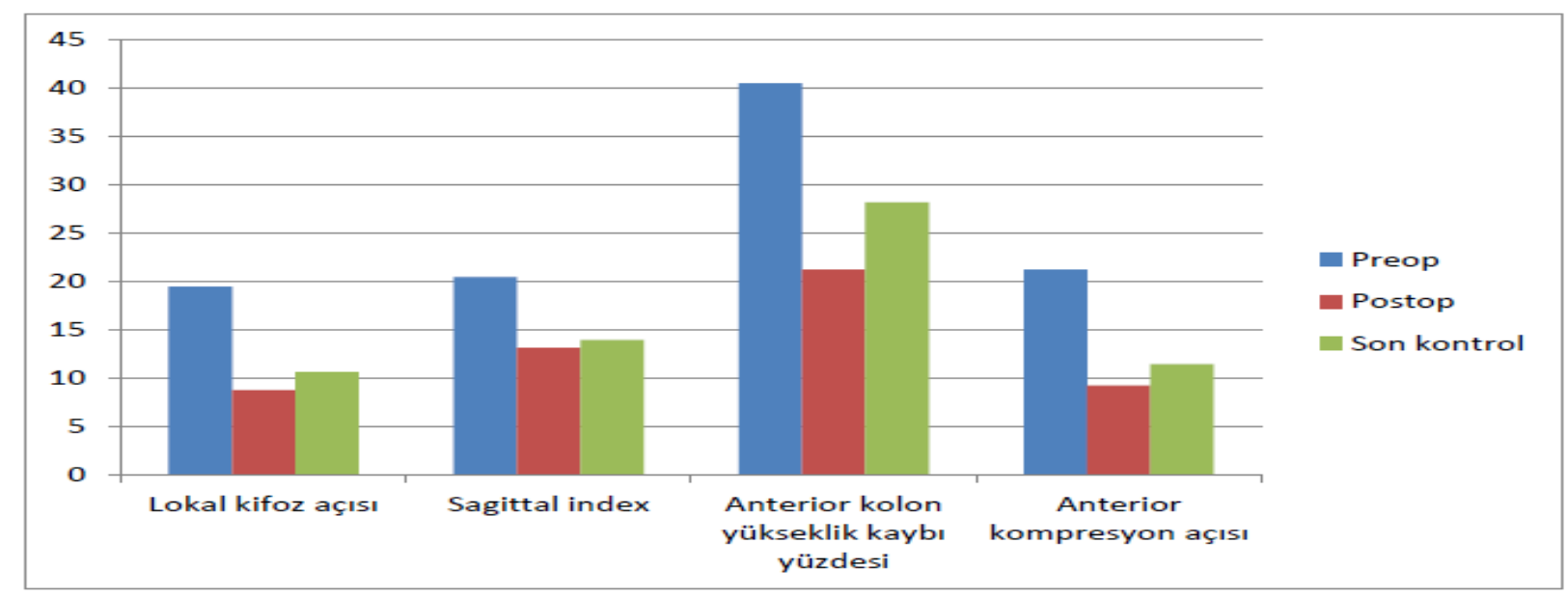

Şekil 2. Tanımlayıcı Analiz Sonuçları

$\mathrm{Bu}$ bulgulara göre kanal remodelasyon oranında artış olduğunda hastaların Oswestry, VAS ve Roland-Moris anket skorlarında azalma olduğunu saptadık.

TLISS puanı artıkça VAS skoru da artmaktadır. Bu ilişki Spearman's Rho testine göre istatistiksel olarak anlamlıdır ( $\mathrm{P}<0,05 ; \mathrm{r}=0,447)$. TLISS puanı artıkça Oswestry skoru da artmaktadır. Bu ilişki Spearman's Rho testine göre istatistiksel olarak anlamlıdır $(\mathrm{P}<0,05$; $\mathrm{r}=0,499)$. TLISS puanı artıkça Roland-Morris skoru da artmaktadır. Bu ilişki Spearman's Rho testine göre istatistiksel olarak anlamlıdır $(\mathrm{P}<0,05 ; \mathrm{r}=0,390)$

Posterior enstrumantasyon sonrasında birçok yazar tarafından implant yetmezliği ile karşılaşılabilineceği bildirilmektedir. Alvine ve arkadaşları; \%39 oranında implant yetmezliği bildirmişken[17], Mc Lain ve arkadaşları; \%54 oranında implant yetmezliği ile karşılaştıklarını bildirmişlerdir[18]. Bizim çalışmamızda, bir hastada $(\% 5,9)$ rod kırılması şeklinde implant yetmezliği gözlendi ve hastaya revizyon ameliyatı uygulandi.

\section{Sonuç}

Son yıllarda iş kollarında yüksek enerji kullanımı ve her geçen gün artan trafik kazaları nedeniyle yalnızca ülkemizde değil tüm dünyada torakolomber vertebra kırıkları büyük problem oluşturmaya başlamıştır. Torakolomber omurga kırıklarının tedavisi ve kanal içi restorasyonu günümüzde halen tartışılmaktadır. Torakolomber bileşke kırıkların, ameliyat öncesinde hastanın yaşı, kırığın seviyesi, kırığın tipi, kanala uzanım miktarı dikkate alınarak değerlendirilmesi ve hangi tip tedavinin yeterli tespitle kanal içi restorasyonu sağlayacağına karar verilmelidir.

Tanı esnasında nörolojik defisit var ise ve kırık stabil değilse cerrahi girişim endikasyonu mevcuttur [19]. Birçok yazar genel olarak kırığın stabilitesine karar vermekte Denis'in 3 kolon teorisini kullanmaktadır [20,21]. Üç kolon teorisini temel alan bilgisayarlı tomografi ve manyetik rezonans görüntüleme çalışmaları, torakolomber bölgede, orta kolonda osteoligamentöz yapının hasarlı olduğu kırıkları instabil olarak kabul etmişlerdir. Son yıllarda, posterior ligamentöz kompleksin stabilitede önemi anlaşılmış ve kompresyon kırı̆̆ı olan hastalarda, bu yapının hasarı ile instabil hale geçişi üzerinde durulmuştur [22,23].

Biz çalışmamızda hastaların ameliyat sonrası lokal kifoz açısı, sagittal indeks, anterior kolon yüksekliğinin düzeltilmesi ve anterior kompresyon açısının azalması açısından radyolojik fayda gördüklerini saptadık. Bu fayda istatistiksel olarak anlamlıydı. $(p<0,05)$. Ameliyat sonrası elde edilen lokal kifoz açısı, sagittal indeks, anterior kompresyon açısı, ve anterior çökme yüzdesi değerlerinde son kontrolde minimal artış vardı ancak bu artış istatistiksel olarak anlamsızdı. ( $p>0,05)$. Knop ve arkadaşları, uzun dönem sonuçlarını elde ettikleri torakolomber patlama kırığı olan 62 hastay değerlendirmiştir. Buna göre SI değerinde ameliyat sonrasında öncesine göre anlamlı düzelme saptamış, takipler sırasında ise bu değerde herhangi bir değişiklik olmadığını tespit etmişlerdir. Lokal kifoz açısında ise ameliyat sonrası dönemde lordoz elde edecek şekilde anlamlı düzelme elde ettikleri halde uzun dönemde ortalama $10^{\circ}$ kayıp gözlemişlerdir. Lokal kifoz açısının, ön kolon yükseklik kaybı değerinin ameliyat öncesi fazla olduğu hastalarda daha fazla bozulduğunu bildirmişlerdir. Yaptıkları istatistik çalışma sonunda ise Hannover Omurga Skoru kullanarak değerlendirdikleri klinik sonuçlar ile hiçbir radyolojik parametre arasında ilişki saptamamışlardır. Bu sebeple yazarlar, radyolojik parametrelerin uzun dönem takiplerinde çok değerli olmadıklarını iddia etmişlerdir[24].

Sonuçta pediküler vidalarla yapılan füzyonlu posterior enstrumantasyonun geç dönemde radyolojik olarak istatistiksel anlamlı iyi sonuçları olduğunu saptadık. Bizim çalışmamızda ameliyat öncesi ve sonrası lokal kifoz açısındaki düzelme miktarı ile VAS skoru, Oswestry skoru ve Roland-Morris skoru arasında istatistiksel olarak anlamlı bir ilişki bulunmamıştır. ( $p>$ 0,05) Bizim çalışmamızda ameliyat öncesi ve sonrası sagital indeks düzelme miktarı ile VAS skoru, Oswestry skoru ve Roland-Morris skoru arasinda istatistiksel olarak anlamlı bir ilişki bulunmamıştır(p > 0,05). Ameliyat öncesi ve sonrası anterior kompresyon açısı düzelme miktarı ile VAS skoru, Oswestry skoru ve Roland-Morris skoru arasında istatistiksel olarak anlamlı bir ilişki bulunmamıştır $(\mathrm{p}>0,05)$. Bizim çalışmamızda 
ameliyat öncesi ve sonrası anterior çökme düzelme miktarı ile VAS skoru, Oswestry skoru ve Roland-Morris skoru arasında istatistiksel olarak anlamlı bir ilişki bulunmamıştır $(\mathrm{p}>0,05)$. Andress ve arkadaşları yaptıkları 50 hastanın uzun dönem sonuçlarında klinik değerlendirme amaciyla Hannover Omurga Skoru'nu kullanmışlar ve lokal kifoz açısındaki bozulma ile değişen klinik skorlar arasında anlamlı ilişki bildirmemişlerdir. Genel olarak klinik şikâyetlerin 30 derecenin üzerinde kifoz açısı bulunan hastalarda daha sık olduğunu bildirmişler, fakat bu derece kifoz açısının ameliyat sonrası gelişmesinin çok da sık olmadığını belirtmişlerdir. Çalışmalarında LKA ile klinik sonuçlar arasında ilişki bulunmamasını da bu nedene bağlamışlardır. Çünkü LKA'nın fazla olduğu hastalar genelde posterior kolonun da travmadan etkilendiği ve instabilitenin daha fazla olduğu hastalardır. Knop ve arkadaşları, yaptıkları istatistik çalışma sonunda ise Hannover Omurga Skoru kullanarak değerlendirdikleri klinik sonuçlar ile hiçbir radyolojik parametre arasında ilişki saptamamışlardır. Bu sebeple yazarlar, radyolojik parametrelerin uzun dönem takiplerinde çok değerli olmadıklarını iddia etmişlerdir [25].

Bizim çalışmamıza göre ameliyat sonrası kanal remodelasyon oranı ile VAS skoru, Oswestry skoru ve Roland-Morris skoru arasinda istatistiksel olarak doğrusal negatif bir ilişkinin( $(r=-0,816, r=-0,656 \quad r=-$ 0,808 ) olduğunu saptadık. Bu ilişki istatistiksel olarak çok anlamliydi $(\mathrm{p}<0,05)$. Bu bulgulara göre kanal remodelasyon oranında artış olduğunda hastaların Oswestry ,VAS ve Roland-Moris anket skorlarında azalma olduğunu saptadık ve bu ilişki istatistiksel olarak çok anlamlıydı. Sonuc olarak calısmamızda klınık memnunıyette radyolojik parametrelerdeki düzelmeden ziyade kanal remodelasyonun daha etkin olduğu sonucuna vardik.

\section{Referanslar}

1. Yılmaz G, Acaroğlu E, Torakolomber bölge omurga yaralanmaları, Türkiye Klinikleri Journal of Surgical Medical Sciences, 2006, 2(30), 5-10.

2. White, A.A, Panjabi, M.M, Clinical biomechanics of the spine, 2nd Edition Lippincott Williams \& Wilkins, Philadelphia, 1990, pp: 115 117.

3. Benli, İ.T, Tandoğan, N.R, Kış, M, Tüzüner, M, Mumcu, E.F, Akalın S, Çıtak M, Cotrel -Dubousset instrumentation in the treatment of unstable thoracic and lumbar spine fractures, Archives Orthopaedic Trauma Surgery, 1994, 113, 88 - 92.

4. Eastlack, R.K, Bono, C.M, Fractures anddislocations of the thoracolumbar spine, In: RW, Heckman, J.D, Court-Brown, C.M, (Eds.), Rockwood and Green's Fractures in Adults, Vol. 2, 5th Edition., Lippincott Williams Wilkins,Philadelphia, 2001, 15431580.

5. Knop, C, Fabian, H, Bastian, L, Blauth, M, Late results of thoracolumbar fractures after posterior instrumentation and transpedicular bone grafting, Spine, 2001, 26 (1), 88-89.

6. Marco, R.A, Kushwaha, V.P, Thoracolumbar burstfractures treated with posterior decompression and pedicle screw instrumentationsupplemented with balloon - assisted vertebroplasty and calcium phosphate reconstruction, Journal of Bone and Joint Surgery, 2009, $91-\mathrm{A}(1), 20-28$.

7. McLain, R.F, Burkus, J.K, Benson, D.R, Segmental instrumentation for thoracic and thoracolumbar fractures: prospective analysis constructs survival and five - year follow, Spine, 2001, 1 (5), 310 323.

8. Scholl, B.M, Theiss, S.M, Kirkpatrick, J.S, Short segment fixation of thoracolumbar burst fractures, Orthopaedics, 2006, 29 (8), 703 -708. 9. Vaccaro, A.R, Kim, D.H, Brodke, D.S, Harris, M, Chapman, J, Schildhauer, T, Routt, M.L.C, Sasso, R.C, Diagnosis and Management of Thoracolumbar Spine Fractures. An Instructional Course Lecture, American Academy of Orthopaedic Surgeons, Journal of Bone and Joint Surgery American, volume 2003, 85-A, 2455-70.

10. Zdeblick, T.A, Sasso, R.C, Vaccaro, A.R, Chapman, J.R, Harris, M.B, Surgical treatment of thoracolumbar fractures, Instructional Course Lectures, 2009, 58, 639- 644.

11. Roy-Camille, R, Saillant, G, Mazel, C, Plating of Thoracic, Thoracolumbar and Lumbar Injuries with Pedicle Screw Plates, Orthopedic Clinics of North America, 17, 147-159, 1986

12. Gertzbein SD, Court-Brown CM, Marks P, et al, (1988) The neurologic outcome following surgery for spinal fractures, Spine 13, $641-4$.

13. Cotler, J.M, Vernace, J.V, Michalski, J.A, The use of Harrington rods in thoracolumbar fractures, Orthopedic Clinics of North America, $1986,17,87-103$

14. Dickson, J.H, Harrington, P.R, Erwin, W.D, Results of reduction and stabilization of the severely fractured thoracic and lumbar spine, Journal of Bone and Joint Surgery,1978, 60-A, 799-805.

15. Ebelke, D.K, Asher, M.A, Neft, J.R, Kraker, D.P, Survivorship Analysis of VSP Spine Instrumentation in the Treatment of Thoracolumbar and Lumbar Burst Fractures, Spine, 16, 428-432, 1991.

16. Graziano, G.P, Cotrel-Dubousset hook and rod combinations for spine fractures, Journal of Spinal Disorders, 6, 380-385, 1993.

17. Alvine, G.F, Swain, J.M, Asher, M.A et al, (2004) Treatment of thoracolumbarburst fractures with variable screw placement or Isola instrumentation and arthrodesis: case series and literature review, Journal of Spinal Disorder Techniques, 17(4), 251 -64.

18. McLain, R.F, Sparling, E, Benson, D.R, 1993, Early failure of shortsegment pedicle instrumentation of thoracolumbar fractures, A preliminary report, The Journal of Bone and Joint Surgery, 75(2):162-7.

19. Weinstein, J.N, Collalto, P, Lehmann, T.R, Thoracolumbar "burst" fractures treated conservatively: a long-term follow-up, Spine, 1988, 13, 33-38.

20. Denis, F, Armstrong, G.W, Searls, K, Matta, L, Acute thoracolumbar burst fractures in the absence of neuralgic defisit, A comparison between operative and non-operative treatment, Clinical Orthopedics and Related Research, 1984, 189; 1-9.

21. Shen, W.J, Liv T.J, Shen, Y.S, Non operative treatment versus posterior fixation for thoracolumbar junction burst fractures without neurologic defisit, Spine, 2001, 26 (9), 1038 -1045.

22. Saifuddin, A, MRI of acute spinal trauma, Skeletal Radiology, 2001, 30, 237-246.

23. Yazar, T, Acar, B, Yatay konumlu konvansiyonel MRG'de aksiyel kompresyon ve traksiyon uygulaması omurga değerlendirimesi için anlamlı midir? The Journal of Turkish Spinal Surgery, 2009, 20 (4), 11-18.

24. Knop, C, Fabian, H, Bastian, L, Blauth, M, Late results of thoracolumbar fractures after posterior instrumentation and transpedicular bone grafting, Spine, 2001, 26(1), 88-89.

25. McNamara, M.J, Stephens, G.C, Spengler, D.M, Transpedicular short-segment fusions for treatment of lumbar burst fractures, Journal of Spinal Disorders, 1992, 5(2), 183-187.

http://edergi.cbu.edu.tr/ojs/index.php/cbusbed isimli yazarın CBU-SBED başlıklı eseri bu Creative Commons Alıntı-Gayriticari4.0 Uluslararası Lisansı ile lisanslanmıştır.

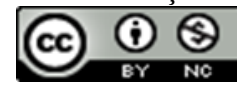

